\title{
Comparison of Endovenous Laser and Radiofrequency Ablation for the Treatment of Varicose Veins
}

\author{
Ahmed Kamal Gabr, MD; Hossam M. Saleh, MD; Sherif Essam MD; \\ Mohamed M. Tawfik, MD.
}

Vascular Surgery Department, Ain Shams University.

Background/aim: Great saphenous vein (GSV) incompetence is the most common cause of superficial venous insufficiency. Endovenous laser ablation (EVLA) and radiofrequency ablation (RFA) are both associated with excellent technical, clinical and patient-reported outcomes for the treatment of varicose veins. The aim of this study is to compare the efficacy, symptomatic outcome and postoperative complications of endovenous thermal ablation using the radiofrequency ablation (VenefitCovidienClosureFast ${ }^{\mathrm{TM}}$ Endovenous Radiofrequency Ablation Catheter) and laser (Nd: YAG laser $1320 \mathrm{~nm}$ CoolTouch ${ }^{\mathrm{TM}}$, Roseville, California) ablation techniques of the great saphenous vein $(G S V)$.

Patients and methods: A total of 123 limbs in 110 patients. In the laser group there was 45 patients with unilateral procedure and 8 patients with bilateral procedures. In the RF group there was 52 patient with unilateral procedure and 5 patients with bilateral procedures. In patients who required bilateral treatment, procedures were performed on different sessions with a time interval of at least 1 month. In the statistical analysis the differences between the study groups were compared by Chi square ( $\chi 2$ ) test for categorical variables, and student's T test for continuous variables. Values of $P<0.05$ were considered significant.

Results: The study enrolled 110 patients (123 limbs): 53 (48\%) were randomized to EVLA and $57(52 \%)$ to RFA, and 13 (12\%) had bilateral GSV incompetence. At 1 week, one patient in the RFA group had an open GSV and was deemed a failure. Venous duplex examination was done in the post-procedural visits at one week, one month, and 6 months to verify objectively GSV closure as evidenced by absence of GSV flow and recanalization. This duplex follow-up showed complete GSV closure throughout the treated segments in all patients in both groups at all follow-up visits. There was no difference between the 2 groups regarding effectiveness of the procedure. Regarding the post-procedural adverse events there was no recorded cases of deep vein thrombosis (DVT) or paresthesia in both groups. There was a nearly significant difference regarding bruises along the course of the treated GSV, as well as inactivity as measured by the visual analogue scale (VAS) in favor of the laser group noticed at 1-week follow up.

Conclusion: Radiofrequency using VenefitCovidienClosureFast ${ }^{\mathrm{TM}}$ ablation was associated with less postoperative pain, tenderness, ecchymosis and better postoperative recovery and QOL parameters than endovenous laser for thermal ablation of the GSV. However, clinical and quality-of-life improvements were similar at 1 month for the two treatment modalities.

Key words: Varicose veins, endovenous laser, radiofrequency ablation.

\section{Introduction:}

The standard treatment of varicose veins for many years has been surgical ligation and stripping of the affected vein. ${ }^{1}$ Recent years have seenthe development of minimally invasive procedures for the treatment of varicose veins led by a desire to reduce operative trauma and bruising associated with standard surgical techniques. ${ }^{2}$

Currently there are two major thermal endovenous treatments available; Endovenous Laser Ablation (EVLA) and Radiofrequency 
Ablation (RFA). Radiofrequency ablation (RFA) catheter delivers radiofrequency energy to achieve heat-induced venous spasm and collagen shrinkage. It acts by directing radiofrequency (RF) energy through and endovenous electrode catheter to the vessel wall. The mechanism by which RF current heats tissue is resistive heating of a narrow rim of tissue that is in direct contact with the electrode. ${ }^{3}$ Endovenous laser ablation (ELA) allows delivery of laser energy directly into the blood vessel lumen in order to produce endothelial and vein wall damage with subsequent fibrosis. 4

The aim of this work is to compare the efficacy, symptomatic outcome and postoperative complications of endovenous thermal ablation using the radiofrequency ablation (VenefitCovidienClosureFast ${ }^{\mathrm{TM}}$ Endovenous Radiofrequency Ablation Catheter) and laser (Nd: YAG laser $1320 \mathrm{~nm}$ CoolTouch $^{\mathrm{TM}}$, Roseville, California) ablation techniques of the great saphenous vein (GSV).

\section{Patients and methods:}

We conducted our study in a prospective non randomized fashion at 4 tertiary referral centers in the Middle East.

Inclusion criteria:

- Age between 18 and 70 years, both sexes.

- All patients have to have venous disease according to CEAP classification (Clinical, etiological, anatomical, and pathological) (C2-4), primary (Ep), Superficial (As) and reflux only (Pr).

- Duplex scan confirmed GSV incompetence with more than 0.5 second reflux duration on duplex examination

- Patient fit for a general/regional anaesthesia.

- Physical condition allowing ambulation after the procedure

Exclusion criteria:

- Varicose veins withoutGSV incompetence on duplex scan.

- History of deep vein thrombosis or pulmonary embolism.

- Highly tortuous GSV above the knee felt to be unsuitable for catheterization

- GSV diameter $<3 \mathrm{~mm}$ or $>12 \mathrm{~mm}$ in the supine position.

- Thrombus in the GSV.

- Patients with a pacemaker or internal defibrillator.

- Concomitant peripheral arterial disease (ankle-brachial pressure index $<0.9$ ).

- Patients who are pregnant or breastfeeding (concerns related to anesthetic use and heated blood effluent that may pass through the placenta to the fetus).

- Previous venous reoperations.

Procedure:

US-guided percutaneous access followed by perivenous tumescent anesthesia with $0.1 \%$ lidocaine with epinephrine was performed before thermal ablation. RF ablation was performed with an intraluminally placed Closure- FAST device with a $7-\mathrm{cm}$ heating element. After positioning the catheter tip 2 $\mathrm{cm}$ from the saphenofemoral junction (SFJ), segmental energy delivery at $120^{\circ} \mathrm{C}$ was delivered in 20-second cycles. Two cycles were applied to the proximal vein, followed by one cycle to the remaining venous segments. The EVL group was treated with a laser at frequency of $40 \mathrm{~Hz}$ and 7 watts and withdrawal using the dedicated automated fiber pull-back device (JouleTracker) to control the laser fiber pull-back in a standardized fashion and adjust the pull-back speed to $0.5 \mathrm{~mm} /$ second in the proximal $10 \mathrm{~cm}$ of the vein guided by the aiming beam to deliver fluence (joules/ linear centimeter vein length) of 140 joules and then increased the speed to $1 \mathrm{~mm} /$ second for the rest of the ablated GSV to deliver fluence of 70 joules. After treatment, the limbs were wrapped with compression bandages and class II compression stockings; subjects were instructed to ambulate frequently. After 24-72 hours, bandages were removed and subjects were instructed to continue to use the compression stockings for 1 week. At 24-72 hours, postprocedural duplex US was performed to assess the status of vein occlusion and thrombosis. Follow-up done at 1 week, 1 month, and 6 months after the procedure. 
Patients were asked to complete a questionnaire at each visit that focused on pain assessment and QOL issues. Visits at 1 and 2 weeks were limited to clinical assessment and patient questionnaires. The final visit at 1 month included duplex ultrasonography. Multiple stab phlebectomies using the microphlebectomy hooks are done as needed under the same anaesthetic.

Study end points:

1-Symptomatic outcome measured by the revised Venous Clinical Severity Score $(\mathrm{rVCSS})^{5}$ at 1 month, and 6 months follow up.

2- Duplex follow up at 1 week, 1 month, and 6 months for effectiveness of GSV closure as evidenced by absence of GSV flow and recanalization.

3- Post-procedural adverse events:

- Inactivity: A $10 \mathrm{~cm}$ visual analogue scale (VAS) is used for self-assessment of inactivity. Patients will be asked to return to normal activity as soon as they wished. VAS is scored as to how active patients were on a scale of 1-10.

- Bruises, and haematomas along the course of the treated GSV segment not related to phlebectomies.

- Paresthesia.

- DVT.

The post-procedural adverse events analysis was done at the 1 week and at the 1 month follow-up visits only because these events were expected to occur within 1 month.

Symptomatic outcome assessment using of the revised Venous Clinical Severity Score (rVCSS) which was designed to be more descriptive and responsive to changes in disease severity over time or in response to treatment.

\section{Statistics:}

Statistical analysis: Differences between the study groups were compared by Chi square $\left(\chi^{2}\right)$ test for categorical variables, and student's $T$ test for continuous variables. Values of $\mathrm{P}<0.05$ were considered significant.

\section{Results:}

Our study was conducted from December 2011 and November 2013. We operated on a total of 123 limbs in 110 patients. In the laser group there was 45 patients with unilateral procedure and 8 patients with bilateral procedures. In the RF group there was 52 patient with unilateral procedure and 5 patients with bilateral procedures. In patients who required bilateral treatment, procedures were performed on different sessions with a time interval of at least 1 month. The baseline demographic characteristics of both groups are outlined in Table (2).

According to patients' demographics, both groups were matched regarding age, sex, clinical presentation, and GSV diameter with no significant difference between the two groups.

Both procedures did not differ significantly regarding procedure time and type of anesthesia used and the performance of adjunctive phlebectomies as shown in Table (3).

The clinical improvement was recorded at presentation and during follow up according to (rVCSS) at 1 month, and 6 months post procedure as shown in Table (4).

The data shown in table 4 shows no statistically significant difference between the 2 groups on follow up regarding the clinical outcome as judged by the rVCSS.

Venous occlusion: Duplex examination was done at the following visits at 1 week, 1 month, and 6 months post procedure to verify objectively GSV closure as evidenced by absence of GSV flow and recanalization. This duplex follow up, showed complete GSV closure throughout the treated segments in all patients in both groups at all follow up visits. This finding points out that there was no difference between the 2 groups regarding effectiveness of the procedure.

Regarding the post-procedural adverse events there was no recorded cases of deep vein thrombosis (DVT) or paresthesia in both groups. There was a nearly significant difference regarding bruises along the course of the treated GSV, as well as inactivity as measured by the visual analogue scale (VAS) 
in favor of the laser group noticed at 1-week follow up as shown in Table (5).

\section{Discussion:}

Several studies have compared RF or EVL with traditional varicose veins surgery, ${ }^{6-10}$ however studies comparing EVL with RF are scarce, and findings have been inconclusive. ${ }^{11-13}$ These studies mostly compare the safety and efficacy of either endoluminal technique. ${ }^{11}$ Morrison ${ }^{12}$ published a retrospective comparison of RF and laser vein ablation with 1-year followup in which 50 patients were randomized to undergo treatment with bipolar RF or 810$\mathrm{nm}$ pulsed laser vein ablation. Postoperative bruising and pain were greater with laser treatment, and primary GSV occlusion rates were better with RF (80\%) than with laser $(66 \% ; \mathrm{P} \pm .0500) .{ }^{12}$

Our study focused on postoperative recovery differences between RF and EVL in a prospective, randomized manner, with a 1 month follow-up. The majority (86\%) of the patients in both treatment groups were enrolled for symptom relief. Postoperative pain, tenderness, ecchymosis, and phlebitis were more prevalent in the laser-treated limbs, likely resulting from high treatment temperatures and perforation of the vein wall by laser energy with extravasation of boiled blood from the treated vein. All scores referable to pain, ecchymosis, and tenderness were statistically lower in the RF group at 48 hours, 1 week, and 2 weeks. Minor complications were more prevalent in the EVL group $(\mathrm{P}=.031)$; there were no major complications in both groups. All QOL measures were statistically better in the RF group at 48 hours, 1 week, and 2 weeks.

In the trial of RF versus vein stripping reported by Lurie et al, ${ }^{14}$ mean VCSSs were reduced from a pretreatment score of 4.8 to 2.5 at 3 weeks after treatment. This is similar to the extent of rVCSS reduction seen in the present trial, in which the rVCSS of 4.5 at baseline decreased at each follow-up visit, ending at 2.8 at 1 month after treatment. Patients treated with EVL also experienced a mean reduction of $\mathrm{rVCSS}$ from baseline to 1 month after treatment (4.9 to 3.1). However, for the follow-up periods of 48 hours, 1 week, and 2 weeks, the average rVCSS of patients treated with EVL were 6.3, 6, and 5.4, all of which were higher than pretreatment levels. This suggests that patients treated with EVL, on average, take longer time to show improvement beyond pretreatment levels. We observed excellent correction of parameters linked to venous reflux and, the venous hypertension secondary to GSV incompetence in both groups.

The RF procedure is better tolerated by patients because controlled heating avoids the vein perforations that could be seen with EVL. The linear endovenous energy density is frequently used to compare energy dosing in endovenous procedures. With the first generation (i.e., bipolar) RF device, the catheter pullback velocity had to be slow enough to allow resistive heating of the vein wall to a target temperature of $85^{\circ} \mathrm{C}$. With the ClosureFast catheter, the temperature is kept stable at $120^{\circ} \mathrm{C}$ during a 20 -second treatment cycle. At the SFJ, a second cycle of energy is delivered, averaging a linear endovenous energy density of $116.2 \mathrm{~J} / \mathrm{cm} \pm 11.6$ for the first $7 \mathrm{~cm}$ of vein juxtaposed to the SFJ to ensure good vein closure at this critical site. ${ }^{15}$ Distal to the SFJ, $68.2 \mathrm{~J} / \mathrm{cm} \pm 17.5$ is delivered to each $7-\mathrm{cm}$ treatment site. This aggressive "double energy cycle" at the zone of the SFJ is supported by a study performed by Almeida and Raines11 in which most recanalizations occurred in the first 12 months and developed in the GSV proximal to the posterior thigh circumflex vein at the SFJ. The posterior thigh circumflex vein, when large, drains cooler blood $\left(37^{\circ} \mathrm{C}\right)$ into the treatment segment, and does not allow proper heat-induced closure of the SFJ; therefore, the SFJ requires more energy to close. ${ }^{11}$

Laser wavelengths based on the affinity of hemoglobin for infrared light have been effective in destroying incompetent veins at the expense of causing robust perivenous inflammation. To overcome the problem of venous perforation, EVL technology continues moving further toward the development of longer wavelengths targeting 


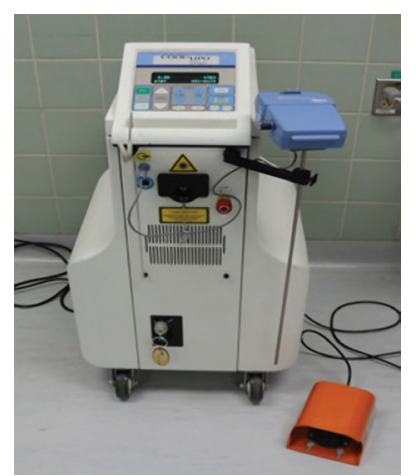

Figure (1): Cool-Touch 1320nm Nd: YAG endovenous laser with automatic pull-back device.

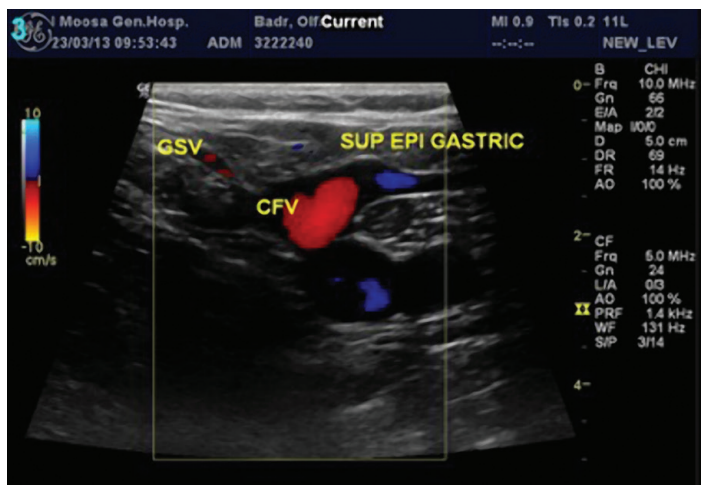

Figure (3): 7 days post-radiofrequency ablation venous duplex ultrasonography showing diminished flow in the great saphenous vein at the saphenofemoral junction.

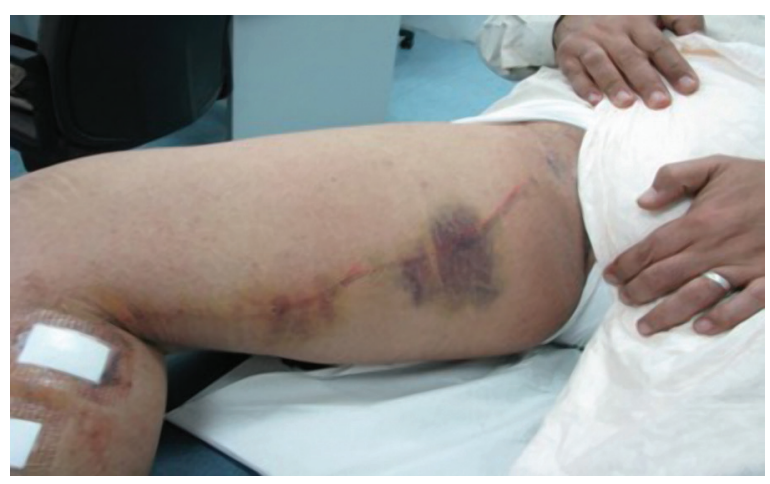

Figure (2): Right thigh ecchymosis following endovenous laser ablation.
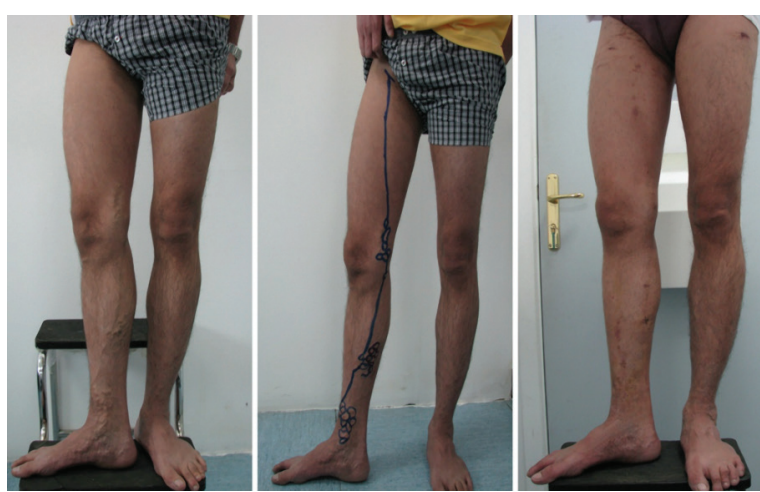

Figure (3): Pre-procedural photograph for right lower limb truncal varicose veins underwent radiofrequency ablation.

Table 1. Revised Venous Clinical Severity Score

\begin{tabular}{|c|c|c|c|c|}
\hline & None: 0 & Mild: 1 & Moderate: 2 & Severe: 3 \\
\hline $\begin{array}{l}\text { Pain } \\
\text { Or other discomfort (ie, } \\
\text { aching, heaviness, fatigue, } \\
\text { soreness, burning) } \\
\text { Presumes venous origin }\end{array}$ & & $\begin{array}{l}\text { Occasional } \\
\text { pain or other } \\
\text { discomfort } \\
\text { (ie, not } \\
\text { restricting } \\
\text { regular daily } \\
\text { activities) }\end{array}$ & $\begin{array}{l}\text { Daily pain } \\
\text { or other } \\
\text { discomfort } \\
\text { (ie, interfering } \\
\text { with but not } \\
\text { preventing } \\
\text { regular daily } \\
\text { activities) }\end{array}$ & $\begin{array}{l}\text { Daily pain or } \\
\text { discomfort } \\
\text { (ie, limits } \\
\text { most regular } \\
\text { daily } \\
\text { activities) }\end{array}$ \\
\hline $\begin{array}{l}\text { Varicose veins } \\
\text { "Varicose" veins must be } \geq 3 \\
\text { mm in diameter to qualify } \\
\text { in the standing position. }\end{array}$ & & $\begin{array}{l}\text { Few: Scattered } \\
\text { (ie, isolated } \\
\text { branch } \\
\text { varicosities or } \\
\text { clusters) } \\
\text { Also includes } \\
\text { corona } \\
\text { phlebectatica } \\
\text { (ankle flare) }\end{array}$ & $\begin{array}{l}\text { Confined to calf } \\
\text { or thigh }\end{array}$ & $\begin{array}{c}\text { Involves calf } \\
\text { and thigh }\end{array}$ \\
\hline
\end{tabular}




\begin{tabular}{|c|c|c|c|c|}
\hline & None: 0 & Mild: 1 & Moderate: 2 & Severe: 3 \\
\hline $\begin{array}{l}\text { Venous edema } \\
\text { Presumes venous origin }\end{array}$ & & $\begin{array}{l}\text { Limited to foot } \\
\text { and ankle area }\end{array}$ & $\begin{array}{l}\text { Extends above } \\
\text { ankle but } \\
\text { below knee }\end{array}$ & $\begin{array}{l}\text { Extends to knee } \\
\text { and above }\end{array}$ \\
\hline $\begin{array}{l}\text { Skin pigmentation } \\
\text { Presumes venous origin } \\
\text { Does not include focal } \\
\text { pigmentation over varicose } \\
\text { veins or pigmentation due } \\
\text { to other chronic diseases }\end{array}$ & $\begin{array}{l}\text { None or } \\
\text { focal }\end{array}$ & $\begin{array}{l}\text { Limited to } \\
\text { perimalleolar } \\
\text { area }\end{array}$ & $\begin{array}{l}\text { Diffuse over } \\
\text { lower third of } \\
\text { calf }\end{array}$ & $\begin{array}{l}\text { Wider } \\
\text { distribution } \\
\text { above lower } \\
\text { third of calf }\end{array}$ \\
\hline $\begin{array}{l}\text { Inflammation } \\
\text { More than just recent } \\
\text { pigmentation (ie, } \\
\text { erythema, cellulitis, } \\
\text { venous eczema, } \\
\text { dermatitis) }\end{array}$ & & $\begin{array}{l}\text { Limited to } \\
\text { perimalleolar } \\
\text { area }\end{array}$ & $\begin{array}{l}\text { Diffuse over } \\
\text { lower third of } \\
\text { calf }\end{array}$ & $\begin{array}{l}\text { Wider } \\
\text { distribution } \\
\text { above lower } \\
\text { third of calf }\end{array}$ \\
\hline $\begin{array}{l}\text { Induration } \\
\text { Presumes venous origin } \\
\text { of secondary skin and } \\
\text { subcutaneous changes } \\
\text { (ie, chronic edema with } \\
\text { fibrosis, hypodermitis). } \\
\text { Includes white atrophy } \\
\text { and lipodermatosclerosis }\end{array}$ & & $\begin{array}{l}\text { Limited to } \\
\text { perimalleolar } \\
\text { area }\end{array}$ & $\begin{array}{l}\text { Diffuse over } \\
\text { lower third of } \\
\text { calf }\end{array}$ & $\begin{array}{l}\text { Wider } \\
\text { distribution } \\
\text { above lower } \\
\text { third of calf }\end{array}$ \\
\hline Active ulcer number & 0 & 1 & 2 & $\geq 3$ \\
\hline $\begin{array}{l}\text { Active ulcer duration } \\
\text { (longest active) }\end{array}$ & N/A & $<3 \mathrm{mo}$ & $>3$ mo but $<1$ y & $\begin{array}{l}\text { Not healed for } \\
>1 \mathrm{y}\end{array}$ \\
\hline $\begin{array}{l}\text { Active ulcer size } \\
\text { (largest active) }\end{array}$ & $\mathrm{N} / \mathrm{A}$ & Diameter $<2 \mathrm{~cm}$ & $\begin{array}{c}\text { Diameter } \\
2-6 \mathrm{~cm}\end{array}$ & Diameter $>6 \mathrm{~cm}$ \\
\hline Use of compression therapy & $\begin{array}{c}0 \\
\text { Not used }\end{array}$ & $\begin{array}{c}1 \\
\text { Intermittent use } \\
\text { of stockings }\end{array}$ & $\begin{array}{c}2 \\
\text { Wears stockings } \\
\text { most days }\end{array}$ & \begin{tabular}{|l}
\multicolumn{1}{c}{3} \\
Full \\
compliance: \\
Stockings
\end{tabular} \\
\hline
\end{tabular}

the last peak of water absorption; the idea being that hemoglobin absorption is totally bypassed, allowing more robust absorption of laser photons by interstitial water in the vein wall. By targeting the vein wall, EVL may improve its postoperative recovery profile. Interestingly, targeting of the vein wall exclusively has always been the goal of $\mathrm{RF}$ ablation. This has been true from the first device operating at $85^{\circ} \mathrm{C}$ to the contemporary ClosureFast catheter operating at $120^{\circ} \mathrm{C}$. In the original bipolar RF ablation procedure, the vein wall act as a resistive element for transfer of energy from anode to cathode; so the vein wall is the direct recipient of conducted heat from a 7-cm-long heating element. ${ }^{16}$

This study demonstrated that RF resulted in significantly less pain than 1320-nm EVL for varicose veins. The degree of improvement in the rVCSS was similar to that reported in other randomized trials. ${ }^{7,14,17}$ The results of the present study support the findings of other studies that have shown less postoperative pain after RF, 12,16,19-21 but failed to show differences in outcomes after 1 month. ${ }^{16}$ 
Table 2: Patient demographics

\begin{tabular}{|l|l|l|l|}
\hline & Group A (Laser) & Group B (RF) & P value \\
\hline Number of patients & 53 & 57 & \\
\hline Number of legs treated & 61 & 62 & \\
\hline Male:Female (n) & $20: 33$ & $24: 33$ & $\mathrm{P}=0.25$ \\
\hline Age (years,mean+/-SD) & $35.8(+/-11.9)$ & $33.6(+/-12.1)$ & $\mathrm{P}=0.3$ \\
\hline Clinical presentation C2 (n of legs, $\%)$ & $11(\%)$ & $9(\%)$ & $\mathrm{X} 2=0.05$ \\
\hline Clinical presentation C3 (n of legs, $\%)$ & $33(\%)$ & $38(\%)$ & $\mathrm{X} 2=0.225$ \\
\hline Clinical presentation C4 (n of legs, $\%)$ & $17(\%)$ & $15(\%)$ & $\mathrm{X} 2=0.031$ \\
\hline GSV diameter(mean+/-SD & $8.2(+/-1.95)$ & $7.9(+/-2.1)$ & $\mathrm{P}=0.58$ \\
\hline
\end{tabular}

GSV: Great saphenous vein, N: Number, SD: Standard deviation, Chi-Square value needed to reject null hypothesis $=3.841$, values of $\mathrm{P}<0.05$ were considered significant.

Table 3: Procedure time, type of anesthesia, and adjunctive phlebectomies

\begin{tabular}{|l|l|l|l|}
\hline & Group A (Laser) & Group B (RF) & P value \\
\hline Procedure time (min) (mean+/- SD) & $26(+/-7.6)$ & $29.5(+/-6.8)$ & $\mathrm{P}=0.3$ \\
\hline Regional anesthesia (n,\%) & $32(52.4 \%)$ & $37(59.6 \%)$ & $\mathrm{X} 2=0.232$ \\
\hline Tumescent anesthesia (n,\%) & $29(47.6 \%)$ & $25(40.4 \%)$ & $\mathrm{X} 2=0.167$ \\
\hline Adjunctive phlebectomies(n,\%) & $39(63.9 \%)$ & $43(69.3 \%)$ & $\mathrm{X} 2=0.11$ \\
\hline
\end{tabular}

Chi-Square value needed to reject null hypothesis $=3.841$, values of $\mathrm{P}<0.05$ were considered significant.

Table 4: RVCSS difference between the two groups

\begin{tabular}{|l|l|l|l|}
\hline & Group A (Laser) & Group B (RF) & P value \\
\hline RVCSS baseline (mean, SD) & $7.065(+/-2.272)$ & $6.919(+/-2.106)$ & $\mathrm{P}=0.355$ \\
\hline RVCSS 1 month (mean, SD) & $0.655(+/-0.655)$ & $0.580(+/-0.641)$ & $\mathrm{P}=0.260$ \\
\hline RVCSS 6 months (mean, SD) & $0.377(+/-0.552)$ & $0.290(+/-0.492)$ & $\mathrm{P}=0.179$ \\
\hline
\end{tabular}

RVCSS: Revised venous clinical severity score, values of $\mathrm{P}<0.05$ were considered significant

Table 5: Post-procedural adverse events in the two groups

\begin{tabular}{|l|l|l|l|}
\hline & Group A (Laser) & Group B (RF) & \multicolumn{1}{|c|}{ P value } \\
\hline Bruises at 1 week (n,\%) & $24(39.3 \%)$ & $40(64.5 \%)$ & $\mathrm{X} 2=3.516$ \\
\hline Bruises at 1 month (n,\%) & $1(1.6 \%)$ & $3(4.8 \%)$ & $\mathrm{X} 2=0.25$ \\
\hline Inactivity (VAS) at 1 week (mean, SD) & $8.4(+/-1.6)$ & $5(+/-0.9)$ & $\mathrm{P}=0.06$ \\
\hline $\begin{array}{l}\text { Inactivity (VAS) at 1 month (mean, } \\
\text { SD) }\end{array}$ & $10(+/-0.6)$ & $9(+/-0.7)$ & $\mathrm{P}=0.260$ \\
\hline
\end{tabular}

Chi-Square value needed to reject null hypothesis $=3.841$, values of $\mathrm{P}<0.05$ were considered significant.

\section{Conclusion:}

RF using VenefitCovidienClosureFast ${ }^{\mathrm{TM}}$ ablation was associated with less postoperative pain, tenderness, ecchymosis and better postoperative recovery and QOL parameters than EVL for thermal ablation of the GSV. However, clinical and quality-oflife improvements were similar at 1 month for the two treatment modalities. 


\section{Reference:}

1- Theivacumar NS, Darwood R, Gough MJ: Neovascularisation and recurrence 2 years after varicose vein treatment for saphenofemoral and great saphenous vein reflux: A comparison of surgery and endovenous laser ablation. Eur J Vasc Endovasc Surg 2009; 38: 203-207.

2- Goode SD, Kuhan G, Altaf N, Simpson R, Beech A, Richards T et al: Suitability of varicose veins for endovenous treatments. Cardiovasc Intervent Radiol 2009; 32: 988-991.

3- Shepherd AC, Gohel MS, Lim CS, Hamish M, Davies AH: The treatment of varicose veins: An investigation of patient preferences and expectations. Phlebology 2010; 25(2): 54-65.

4- Rasmussen LH, Bjoern L, Lawaetz M, Blemings A, Lawaetz B, Eklof B: Randomized trial comparing endovenous laser ablation of the great saphenous vein with high ligation and stripping in patients with varicose veins: Short-term results. $J$ Vasc Surg 2007; 46: 308-315.

5- Vasquez MA, Rabe E, McLafferty RB, Shortell CK, Marston WA, Gillespie $\mathrm{D}$, et al: Revision of the venous clinical severity score: Venous outcomes consensus statement: Special communication of the American Venous Forum Ad Hoc Outcomes Working Group. Journal of Vascular Surgery 2010; 52(5): 1387-1396.

6- Lurie F, Creton D, Eklof B, Kabnick LS, Kistner RL, Pichot O, et al: Prospective randomized study of endovenous radiofrequency obliteration (closure procedure) versus ligation and stripping in a selected patient population (EVOLVeS Study). J Vasc Surg 2003; 38: 207-214.

7- Darwood RJ, Theivacumar N, Dellagrammaticas D, Mavor AI, Gough MJ: Randomized clinical trial comparing endovenous laser ablation with surgery for the treatment of primary great saphenous varicose veins. Br J Surg 2008; 95: 294-301.

8- Mekako AI, Hatfield J, Bryce J, Lee D, McCollum PT, Chetter I: A nonrandomised controlled trial of endovenous laser therapy and surgery in the treatment of varicose veins. Ann VascSurg 2006; 20: 451-457.
9- Nesbitt C, Eifell RK, Coyne P, Badri H, Bhattacharya V, Stansby G: Endovenous ablation (radiofrequency and laser) and foam sclerotherapy versus conventional surgery for great saphenous vein varices. Cochrane Database Syst Rev 2011; 5(10).

10- HelmyElKaffas K, ElKashef O, ElBaz $\mathrm{W}$ : Great saphenous vein radiofrequency ablation versus standard stripping in the management of primary varicose veins-a randomized clinical trial. Angiology 2011; 3: 49-54.

11- Almeida JI, Raines JK: Radiofrequency ablation and laser ablation in the treatment of varicose veins. Ann Vasc Surg 2006; 20: 547-552.

12- Morrison N: Saphenous ablation: What are the choices, laser or RF energy. Semin Vasc Surg 2005; 18: 15-18.

13- Puggioni A, Kalra M, Carmo M, Mozes G, Gloviczki P: Endovenous laser therapy and radiofrequency ablation of the great saphenous vein: Analysis of early efficacy and complications. J VascSurg 2005; 42: 488-493.

14- Lurie F, Creton D, Eklof B, Kabnick LS, Kistner RL, Pichot $\mathrm{O}$, et al: Prospective randomised study of endovenous radiofrequency obliteration (Closure) versus ligation and vein stripping (EVOLVeS): Two-year followup. Eur J Vasc Endovasc Surg 2005; 29: 67-73.

15- Proebstle TM, Vago B, Alm J, Göckeritz $\mathrm{O}$, Lebard C, Pichot O, et al: Treatment of the incompetent great saphenous vein by endovenous radiofrequency powered segmental thermal ablation: First clinical experience. J Vasc Surg 2008; 47: 151-156.

16- Almeida JI, Kaufman J, G“ ockeritz O, Chopra P, Evans MT, Hoheim DF, et al: Radiofrequency endovenous ClosureFast versus laser ablation for the treatment of great saphenous reflux: A multicenter, singleblinded, randomized study (RECOVERY study). J VascInterv Radiol 2009; 20: 752-759.

17- Shepherd AC, Gohel MS, Lim CS, Hamish M, Davies AH: Pain following 1320-nm endovenous laser ablation and segmental radiofrequency ablation for varicose veins: A prospective observational study. Vasc Endovascular Surg 2010; 44(3): 212-216. 